\title{
The Evaluation and Selection of Supply Chain Models for Short-Life-Cycle Products
}

\author{
Xuenian Zhao ${ }^{1}$, Qiang Zhou $^{2} \&$ Xia Pan ${ }^{3}$ \\ ${ }^{1}$ Capitaland Limited, China \\ ${ }^{2}$ Hong Kong Shue Yan University, Hong Kong, China \\ ${ }^{3}$ Lingnan College, Sun Yat-sen University, China \\ Correspondence: Xia Pan, Lingnan College, Sun Yat-sen University, 135 Xin Gang Xi Road, Guangzhou \\ 510275, China. E-mail: panxpapers@gmail.com
}

Received: Decemeber 27, 2013

Accepted: March 21, $2014 \quad$ Online Published: April 18, 2014

doi:10.5539/ijbm.v9n5p88

URL: http://dx.doi.org/10.5539/ijbm.v9n5p88

\begin{abstract}
Based on the characteristics of short-life-cycle products and the current status of China's flower industry and apparel industry, this paper analyzes the two most commonly used supply chain models, the direct selling-fixed point mode and the wholesale-agent mode. In addition, within the framework of growth/share matrix (BCG matrix), supply chain models for four categories of enterprises (slim-dog enterprise, problem-enterprise, cow-enterprise and superstar-enterprise) were proposed and analyzed.
\end{abstract}

Keywords: short-life-cycle products, supply chain management, e-commerce, BCG matrix, news vendor model

\section{Introduction}

The fast-changing demand makes products outdated at an increasing rate. Product life-cycle becomes increasingly short. Effective supply chain management is practically important for enterprises dealing with short-life-cycle products. Furthermore, the rapid-developing information technology changes the way of doing business. E-commerce is playing more and more significant role for many companies. Whether e-business model is suitable for short-life-cycle products remains unanswered. Selecting appropriate supply chain models for short- life-cycle products will be a critical issue. At present, the research on the short-life-cycle products supply chain in China is still in the early stage. The purpose of this study is to explore the characteristics of the short-life-cycle products and how to choose a right supply chain model for the enterprises handling short-life-cycle products in the booming market economy in China.

In this paper, we will discuss the characteristics of two traditional supply chain models for short-life-cycle products, and seek the possibilities to employ B2B e-commerce to improve these supply chains. We will analyze the short-life-cycle products industry in the framework of BCG growth/share matrix. Specifically, as the emphasis of this paper, we will employ the news vendor models to investigate some of the modes in the BCG matrix, with the example flower business supply chain. The investigation will enable us to recommend appropriate/optimal choices for the supply chain. In the last, we will use some E-commerce cases in China to example another mode of the BCG matrix.

\section{Literature Review}

The product life cycle refers to the life span of a product consisting of introduction, growth, maturity, and decline stages (Anderson \& Zeithaml, 1984). The short-life-cycle products, or perishable products, experience introduction, growth, maturity, and decline stages very quickly. Demands for such products are also very unstable (Chen \& Xu, 2001), etc.

The typical industries with short-life-cycle products are the agricultural industry (flowers, fruits and vegetables, etc.), fresh food industry (seafood, beer, milk, and bread, etc.), as well as the apparel industry. On the other hand, most traditional manufacturing, except the few for fashioned products which is also of short-life-cycle, is a good example with long-life-cycle products, such as machine tool manufacturing and aircraft manufacturing. Supply chain management for short-life-cycle products is very different from that for long life-cycle products. It requires fast delivery, short distribution channels. These often mean direct transactions with little number of 
layers and sometimes special transport modes. Many effective ways to handle traditional supply chain do not work well for short-life-cycle products. Therefore, supply chain for short-life-cycle products should be more responsive and agile (Milner \& Rosenblatt, 2002). Therefore, it is necessary to reduce intermediaries in such supply chains.

Rapid technological advances and drastic competition make a wide range of long-life-cycle products short life, such as, software and electronic gadgets. It is increasingly important to explore further supply chain management for short-life-cycle products. It is essential to have a right supply chain for a company's products (Fisher, 1997). There is more and more emphasis on academic research that is related with short-life-cycle product supply chain. Milner and Rosenblatt (2002) proved the usefulness of a flexible supply contract to reduce negative correlation of demand across periods. Liu, Chen, Liu and Zhang (2006) studied the co-ordination problems of sale channels for a class of short-life-cycle product. Weng (1999) and Weng and McClurg (2003) explores ways of conceptualizing and studying the power of coordination and strategic alliances within a manufacturing and distribution supply chain. Higuchi and Troutt (2004) used scenario-based dynamic simulations to study the short product life cycle case.

A wide variety of research showed that information sharing in longer life-cycle product supply chain. Information sharing can reduce demand distortion and the negative impact brought about by bullwhip effect (Lee \& Whang, 2000; Raghynathan, 2001). However, short-life-cycle products have only a relatively narrow time window for sales. We do not know whether the research findings can be extended to short-life-cycle products supply chain.

Some enterprises operate in a traditional supply chain; others rely on information technology to build their supply chain. Previous research analyzed decision-making of supply chain members in the traditional and online network mode. Kumar and Ruan (2006) studied whether the manufacturer should increase the network sale channels based on the traditional retail channels. Tsay and Agrawal (2004) found that the increase in direct online sales channels will not necessarily damage the traditional retailers.

\subsection{Traditional Supply Chain Models for Short-Life-Cycle Products}

In the following we employ the flower industry as our example for this issue. We discuss two modes, the direct-fixed point mode and the wholesales-agent mode.

\section{(A) Direct-Fixed Point Mode}

The characteristics of this model is to set up production facility for short-life-cycle products such as flowers and its own sales network in various regions to reach customers directly. The advantage is that enterprises can effectively control the sales channels and enhance marketing and development efforts; at the same time, a corporate brand image could be well established. This mode could expand the visibility and timely acquire the accurate customers' feedback. In addition, it could also save a great deal of circulation costs for enterprises. The main drawbacks are an increased transaction cost for small sales volume from individual consumers and an increased management control costs because of building its own sales networks. This model is more appropriate when customer base is stable.

\section{(B) The Wholesale-Agent Mode}

In such a model, the flower companies identify a group of agents, brokers and wholesalers, to conduct sales to customers. It requires that the enterprise has a strong market exploring capability and a broader market coverage. The advantage of this model is that agents can help an enterprise form a highly efficient and low-cost distribution channels which may contribute to a larger market share. There is a clear division of responsibilities between them. And, the enterprise could adjust the number of agents in a timely manner based on their own needs and the performance of agents.

However, the problem is how to effectively manage and control agents in the network. The agents may not work for the best interest of the enterprise. Information asymmetry causing opportunistic behavior of the agents should be reduced. In China, this model runs into some problems. First, the agents put too much burden on manufacturers which bear the risk of market price fluctuation, resulting in a slower cash flow and a significant increase in funds tie-up. Second, Credibility is the foundation in forming agency relationship. Without business credibility, search cost, contract cost and monitoring cost can be extremely high. Lack of credibility in business transactions is pervasive in transition economy. There is no exception in China.

The traditional supply chains can be improved by adopting E-commerce. Current business competition shifts from individual businesses versus individual businesses to supply chain versus supply chain. The technological development and the shorter product life cycle forced the enterprises to cooperate with others to enhance the 
competitiveness of the supply chain (Fites, 1996). Supply chain members must not only coordinate all internal operations, such as planning, procurement, manufacturing, and sales activities, but also work closely with upstream and downstream partners. Information sharing is an enabler and the basis for better coordination and planning of the supply chain activities. B2B e-commerce is an ideal platform for information sharing. Traditional supply chains include a lot of intermediaries which are the barrier to efficient and effective information sharing. B2B e-commerce can greatly improve the markets efficiency and reduce the search, negotiations and deal-making time and processing costs between buyers and sellers. That may account for the trend towards calling B2B "Benefit-to-Business".

\subsection{The Short-Life-Cycle Products Supply Chains in BCG Matrix}

Boston Consulting Group (BCG) proposed the framework of growth/share matrix which is a useful analytical tool to identify the market positions for enterprises (Allan \& Hammond, 1975). In this section, we analyze short-life-cycle products industry (e.g., flower industry and apparel industry) in the introduced by the. As shown in Table 1, enterprises can be placed on the four quadrants of the matrix, superstar-enterprise (both market share and business growth are high); problem-enterprise (market share growth is low; business growth is high); cow-enterprise (market share growth is high; business growth is low); slim dog-enterprise (both market share and business growth are low).

Table 1. Applying BCG Matrix in short-life-cycle product industry

\begin{tabular}{lll}
\hline & Market share low & Market share high \\
\hline Business growth & Problem Enterprise & Superstar Enterprise \\
high & (B2B farm-direct mode) & (The coexist mode of traditional and e-commerce) \\
Business growth & Slim-Dog Enterprise & Cow Enterprise \\
low & (the traditional mode) & (the "mouse+cement" mode) \\
\hline
\end{tabular}

The above matrix has two dimensions, the relative market share and business growth. In each dimension, the low value and high value spread from left to right or from bottom to top respectively, deploying businesses into four classes.

\section{(A) On the Slim-Dog Enterprise-Traditional Model}

In the flower industry, the slim dog-enterprises are small flower retail shops. Without any potential of business growth and mark share expansion, they generally meet the demands of local communities with limited flowers species and low sales volume. The traditional wholesale-agent mode can be applied to this type of enterprises. The best strategy for them to survive is to be the retail outlets of large flower production and distribution enterprises.

\section{(B) On the Problem Enterprise-B2B Farm-Direct Model}

In the customer dominated market environment, sales channel is the lifeline of an enterprise. Problem-enterprises with high growth but low market share could expand their market shares by being a sales channel for more upstream enterprises. B2B farm-direct business model described below could be a good choice.

In Figure 1, flower shop A establishes a B2B e-commerce business partnership with some flower farms $\mathrm{B}_{1}, \mathrm{~B}_{2}$, $B_{3}$, etc. For example, if customer $C_{1}$ places an order to $A$ via website, and then $A$ contacts the closest farm $B_{1}$ from the $\mathrm{C}_{1} ; \mathrm{B}_{1}$ could immediately pick freshest flowers and deliver them to customers as quickly as possible. 


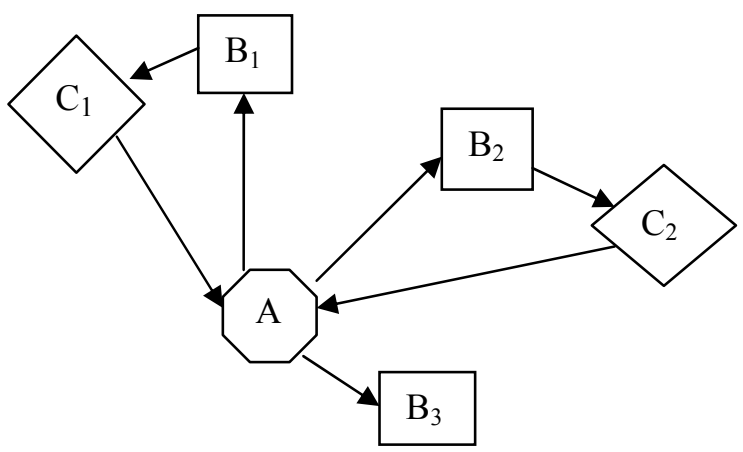

Figure 1. B2B farm-direct mode

In this way, this mode could not only maximize the interests of consumers (the fresh flowers, less waiting time, and convenience), but also reduce transaction costs for upstream and downstream in the supply chain. In addition, company A can also better understand the needs and explore the market through the establishment of the customer information database.

Like the traditional direct sale-fixed point model, this mode sells products directly to end customers. The traditional mode has to set up plants in flower production, having a relative small direct sale market. Nevertheless, through B2B e-commerce partnership model, any flower production base such as farms can directly establish cross-regional and cross-border contact with flower shops. It only needs an agreement for benefit-sharing.

In short, the key here is to develop the Internet business. The supply chain should make full use of information and communication technology to closely link flower farms, carriers, importers and exporters, warehousing, container transport, and consumers, thus enhancing the transparency and visibility of transactions.

\section{(C) The Analysis of Cow-Enterprise- "Mouse + Cement" Model}

The market share of cow enterprise is high but with low profit. A "mouse + cement" model may be appropriate for this type of enterprises to grow further. Simply put, the enterprise will maintain traditional retailing activities and establish online B2B e-commerce platform simultaneously. Information technology plays an increasingly important role in the current procurement management. By sharing information and shortening procurement cycle, procurement cost was lowered and service level was elevated (Keskinocak \& Tayur, 2001), thus operating profit will be increased. In such a hybrid model, the enterprises need to know on what condition a division will perform better than another division in order to divide businesses between traditional division and online division.

In the following we employ the Newsboy model to analyze this cement+mouth mode in depth, especially on when a traditional "cement" cow enterprise should develop its "mouth" arm.

\subsection{Assumptions and Notations}

Consider a supply chain that is composed of a vendor (Company $\mathbf{A}$ ) and a number of flower suppliers (flower farmers). Flower farmers plant flowers. Company A purchases flowers from the flower farmers, and sells flowers through its sales channels. The market demand $\mathbf{X}$ for Company $\mathbf{A}$ is random. If the demand is generally more than the procurement, Company A will lose sales. On the contrary, if the demand is lower than the procurement, Company A will mark down the remaining flowers inventory. This is a typical single-period newsboy problem (Petruzzi \& Dada, 1999).

Scenario 1: In the traditional model, if market demand is in excess of its procurement volume, Company $\mathbf{A}$ is facing the shortage penalties; if market demand is below its purchasing volume, Company $\mathbf{A}$ will return the flowers to the flower farmer with low price (residual value of the proceeds). Correspondingly, the flower farmer may have to bear a cost of return from A. In general, short-life-cycle products suppliers usually offer a return policy to coordinate the supply chain to maintain the long-term cooperative relations, so as to enhance the overall effectiveness of the supply chain (Emmons \& Gilbert, 1998).

Scenario 2: In the "Mouse + cement" model, the flower suppliers and Company A conduct transactions through e-procurement. The assumption is generally similar to Scenario 1; however, both of the suppliers and $\mathbf{A}$ will bear the IT cost, and the unit IT cost of $T_{1}, T_{2}$ will be diminishing with the increase in trading volume (Dai \& Kauffman, 2001). 


\subsection{Notations}

$C$ : unit production cost of flower;

$J_{I}$ and $J_{2}$ : unit transaction costs for the flower supplier and $\mathbf{A}$, respectively;

$U_{I}$ and $U_{2}$ : the wholesale procurement price in two modes, respectively;

$P$ : market retail price of the flowers;

$Q_{I}$ and $Q_{2}$ : procurement quantity of company $\mathbf{A}$ in two modes, respectively;

$S_{1}$ and $S_{2}$ : unit refund to company $\mathbf{A}$ for the excess procurement;

$T_{l}$ and $T_{2}$ : unit cost of IT for flower supplier and company A, respectively;

$x$ : market demand (non-negative continuous random variable);

$f(x)$ and $F(x)$ : probability density function and distribution function of market demand;

Based on the relationship of the parameters, the assumptions are made as follows:

(1) The production capacity of suppliers is infinite, and the cost of production is directly proportional to the number of production;

(2) The flowers are short life cycle product, and inventory holding costs will be ignored as zero;

(3) $U_{1}>U_{2}>C$, because of the B2B e-commerce environment, the competition between flower suppliers will be even more intense;

(4) $F(x)$ is a continuous, differentiable, reversible, and strictly increasing function of the demand $x$.

\subsection{Analysis of the Traditional Model of Procurement}

If Company A and the flower supplier are in a vertical supply chain and consider the overall interest, then transaction costs can be neglected (Petruzzi \& Dada, 1999). And then, the overall supply chain profit is expected to be:

$$
E(Q)=-C \times Q+P \times x \times f(x) d x+P \times Q \times f(x) d x
$$

Correspondingly, the optimal procurement volume of the supply chain is

$$
Q_{11}^{*}=F^{-1} \times[(P \times C) / P]
$$

If the suppliers are independent each other, their profits are maximized independently. Then, the expected profit for the flower supplier is:

$$
E(Q)=\left(U_{1}-C-J_{1}\right) \times Q
$$

If we do not consider the return policy, Company A's profits can be expected as:

$$
E(Q)=-\left(J_{2}+U_{1}\right) \times Q+P \times x \times f(x) d x+P \times Q \times f(x) d x
$$

And the best purchasing quantity ordered by Company $\mathrm{A}$ is

$$
Q_{12}^{*}=F^{-1} \times\left[\left(P-U_{1}-J_{2}\right) / P\right]
$$

It is easy to see that $U_{1}>C$, therefore, $Q_{12} *<Q_{11} *$, that is, the best purchasing quantity of $\mathbf{A}$ is lower than the best procurement volume of the supply chain. However, if the farmers offer the return policy, the procurement of A will reach the best supply chain procurement. If the unit refund amount is $S_{1}$, the best procurement quantity for Company $\mathbf{A}$ is:

Let $Q_{12} *$ be equal to $Q_{11} *$, we have:

$$
Q_{12}^{*}=F^{-1} \times\left[\left(P-U_{1}-J_{2}\right) / P-S_{1}\right]
$$

\subsection{Analysis of "Mouse + Cement" Model}

$$
S_{1}=\left(U_{1}+J_{2}-C\right) \times P /(P \times C)
$$

Similarly, we consider the overall interest of a vertical supply chain composed of the flower supplier and Company A, where the transaction costs can be neglected (Petruzzi \& Dada, 1999). The overall supply chain profit is expected to be:

$$
E(Q)=-C \times Q+P \times x \times f(x) d x+P \times Q \times f(x) d x
$$

The optimal procurement volume of the supply chain is then 


$$
Q_{21}^{*}=F^{-1} \times[(P \times C) / P]
$$

If the suppliers and sellers are decentralized in the supply chain and independent each other, the expected profits for the flower suppliers are maximized separately for their own, that is,

$$
E(Q)=\left(U_{2}-C-T_{1}\right) \times Q
$$

Without considering return policy, the expected profits of Company $\mathbf{A}$ would be:

The best order quantity from Company A should be

$$
E(Q)=-\left(T_{2}+U_{2}\right) \times Q+P \times x \times f(x) d x+P \times Q \times f(x) d x
$$

$$
Q_{22}^{*}=F^{-1} \times\left[\left(P-U_{2}-T_{2}\right) / P\right]
$$

Similarly, if the flower suppliers offer a return policy; we get the unit refund amount as

\section{Comparison}

$$
S_{2}=\left(U_{2}+T_{2}-C\right) \times P /(P \times C)
$$

In the newsboy model, the general assumption is that the demand $x$ is under the uniform distribution $[0, D]$ to reflect the general condition (Petruzzi \& Dada, 1999), that is,

$$
f(x)=1 / D \quad F(x)=X / D \quad F^{-1}(x)=D X
$$

For Company A, the profit under the traditional model will be:

$$
E_{1}=-\left(J_{2}+U_{1}\right) \times Q+\left[P \times x+S_{1} \times\left(Q^{*}-x\right) f(x) d x+P \times Q^{*} \times f(x) d x\right]
$$

The profit under the "mouse + cement" model will be:

$$
\begin{aligned}
& E_{2}=-\left(T_{2}+U_{2}\right) \times Q+\left[P \times x+S_{2} \times\left(Q^{*}-x\right) f(x) d x+P \times Q^{*} \times f(x) d x\right] \\
& E_{2}-E_{1}>0 \Rightarrow \Delta=\left(U_{1}+J_{2}-T_{2}-U_{2}\right) \times Q>0 \Rightarrow T_{2}<U_{1}+J_{2}-U_{2}
\end{aligned}
$$

That is, when the unit IT cost of Company $\mathbf{A}$ is less than $U_{I}+J_{2}-U_{2}$, the profit of $\mathbf{A}$ will be higher than the company's profit in the traditional model. Similarly, considering flower supplier, we have $T_{1}<1 / 2 \times\left(2 J_{1}+J_{2}+U_{2}-U_{1}\right)$. That is, when the unit IT cost for the flower supplier is less than $1 / 2 \times\left(2 J_{1}+J_{2}+U_{2}-U_{1}\right)$, the profit of flower supplier will be higher than that in the traditional model.

We can use a numerical example to show whether a company in the flower industry should employ B2B E-commerce, in the sense of reducing cost and increasing profits. Suppose that the operating data for Company A are as follows: the market demand is subject to the uniform distribution $[0,100]$, the market price of flower: $P$ $=5$, the procurement price in the traditional model: $U_{I}=3.5$, in e-procurement model: $U_{2}=3$; transaction costs: $J_{I}=1, J_{2}=0.8$. If the unit IT cost for the flower supplier, $T_{1}<1 / 2 \times(2 \times 1+0.8+3-3.5)=1.15$, then the profit of the flower supplier in the e-commerce mode will be higher; if the unit IT cost of A, $T_{2}<3.5+0.8-3=1.3$, Company A's profit in the e-commerce mode will be higher than that in the traditional model.

As such, in reality if the necessary parameters are known or estimated appropriately, a "cement" company can determine whether to adopt the B2B way in their business. In short, if the information technology investment was planned carefully, the adoption of e-commerce will achieve a win-win situation.

\section{(D) The Star-Enterprise Model-Revelations from Practices}

Star enterprises are market leaders. They have not only a large market share, but also a fast growth. Their success was attributed to the match of their own distinctive business models with their operating environment. There are no universal supply chain models for these stars. The following cases in Chinese apparel industry convey messages allowing us to understand the supply chain. 


\subsection{Youngor: Traditional Supply Chain Model with Integrated Retail Stores}

Youngor is a traditional apparel enterprise and owns most of domestic market share. Youngor has operated in China for 30 years, serving tens of millions of consumers. $80 \%$ of the current sales are completed by Youngor's own marketing channels. Its businesses touch almost every node in the apparel supply chain, such as, printing and dyeing mill, cotton mills, factories, and even cotton field. Youngor established a logistics center with more than 100 million RMB. Youngor's strategy is to increase the sense of brand recognition by creating one-stop shopping experience for its customers and by integrating retail stores with supplying facilities.

Youngor has ever tried to build its own B2B e-commerce model, however, the senior executives finally realized that they cannot succeed because of the heavy impact on current pricing practices in the sales channel and the difficulty in managing its channel.

\subsection{PPG and Vancl: the E-Commerce Online Marketing Mode}

PPG and Vancl are two leading online shopping brands in apparel industry in China. From nobody to somebody, PPG spent only one and a half years. It became an industry leader and the most dazzling star in apparel industry in 2007. Following PPG, Vancl created in 2008 by Chen Nian who has extensive experience in logistics. Vancl outperformed PPG in sales in only five months. More than $80 \%$ of Vancl shirt is sold directly through the Internet.

PPG and Vancl's innovative business model started with selling men's shirt over Internet. By outsourcing the production and logistics, they enable consumers to buy at a lower price due to the significant cost reduction in sales channel. They also responded to the demands fast. The key to their success is the right match between the products and the supply chain. Men's shirt is more standardized, easier to produce, and can be delivered fast. In addition, male customers feel more comfortable with online shopping.

\section{What We Can Learn from These Cases?}

Although the e-commerce model has its own advantage in terms of flexibility and cost reduction, PPG and Vancl have to bear the risk of outsourcing production and logistics, such as, the possible disruption of the supply chain and the difficulty in maintaining product quality. In addition, e-commerce model needs investment in the IT infrastructure.

As far as Youngor is concerned, it is unwise to completely transform current traditional supply chain model to e-commerce model at present. The fact that Youngor has been able to be the industry leader in apparel industry demonstrated the suitability of traditional model at least in the near future. However, it is necessary to gradually introduce e-commerce platform by developing new brands. Actually, its brands, production facilities, logistics and distribution systems, warehousing, retail experience, and after-sales service can serve as leverage to jump on the bandwagon of e-commerce model.

We estimate that China's online shopping market share will continue to grow in an increasing speed and market share of traditional channels will continue to decline. However, the online model cannot completely replace the traditional model. On the contrary, the development of online direct marketing will drive the development of the traditional model and accelerate the integration of the traditional model and the e-commerce model.

\section{Conclusions}

Is there really one supply chain model for short-life-cycle products that guarantees success? Based on the previous analyses, we know that there is no "One Size Fits All" model. We also cannot say that the selection of supply chain model depends completely on specific and unique situation of an enterprise.

Nowadays, fast changing operating environment has not only made product-life-cycle shorter, but also shorten the life cycle a supply chain model. Any supply chain model has its own merits and weaknesses. Enterprises must adapt to changes in operating environment to select right supply chain model for their short-life-cycle products. No supply chain model is panacea.

\section{References}

Allan, G. B., \& Hammond, J. S. (1975). Note on the Boston Consulting Group Concept of Competitive Analysis and Corporate Strategy. Boston, Mass: Harvard Business School.

Anderson, C. R., \& Zeithaml, C. P. (1984). Stage of the product life cycle, business strategy, and business performance. Academy of Management Journal, 27(1), 5-24. http://dx.doi.org/10.2307/255954

Chen, J., \& Xu, L. (2001). Coordination of the Supply Chain of Seasonal Products. IEEE Transactions on Systems, Man and Cybernetics-Part A: Systems and Humans, 31(6), 524-532. 
http://dx.doi.org/10.1109/3468.983410

Chiang, W., Chhajed, D., \& Hess, J. (2003). Direct Marketing, Indirect Profits: A Strategic Analysis of Dual-Channel Supply-Chain Design. Management Science, 49(1), 1-20. http://dx.doi.org/10.1287/mnsc.49.1.1.12749

Dai, Q., \& Kauffman, R. (2001). Business Models for Internet-Based E-procurement Systems and B2B Electronic Markets: An Exploratory Assessment. Proceeding of the 34th Annual Hawaii International Conference on System Sciences, Hawaii, USA.

Emmons, H., \& Gilbert, S. M. (1998). The Role of Returns Policies in Pricing and Inventory Decisions for Catalogue Goods. Management Science, 44(2), 276-283. http://dx.doi.org/10.1287/mnsc.44.2.276

Fisher, M. L. (1997). What is the right supply chain for your product? Harvard Business Review, 105-116.

Fites, D. V. (1996). Make Your Dealers Your Partners. Harvard Business Review, 74(2), 40-51.

Higuchi, T., \& Troutt, M. D. (2004). Dynamic simulation of the supply chain for a short life cycle product-Lessons from the Tamagotchi case. Computers \& Operations Research, 31, 1097-1114. http://dx.doi.org/10.1016/S0305-0548(03)00067-4

Keskinocak, P., \& Tayur, S. (2001). Quantitative analysis for internet enabled supply chains. Interfaces, 31(2), 70-89. http://dx.doi.org/10.1287/inte.31.2.70.10626

Kumar, N., \& Ruan, R. (2006). On Manufacturer's Complementing the Traditional Retail Channel with A Direct Online Channel. Quantitative Marketing and Economics, 4(3), 289-323. http://dx.doi.org/10.1007/s11129-005-9003-8

Lee, H. L., \& Whang, S. (2000). Information sharing in a supply chain. International Journal of Technology Management, 20(3/4), 373-387. http://dx.doi.org/10.1504/IJTM.2000.002867

Liu, B., Chen, J., Liu, S., \& Zhang, R. (2006). Supply-chain coordination with combined contract for a short-life-cycle product. IEEE Transactions on Systems, Man, and Cybernetics-Part A: Systems And Humans, 36(1), 53-61. http://dx.doi.org/10.1109/TSMCA.2005.859172

Milner, J. M., \& Rosenblatt, M. J. (2002). Flexible supply contracts for short life-cycle goods: the buyer's perspective. Naval Research Logistics, 49, 25-45. http://dx.doi.org/10.1002/nav.10002

Petruzzi, N. C., \& Dada, M. (1999). Pricing and the news-vendor problem: a review with extensions. Operations Research, 47(2), 183-194. http://dx.doi.org/10.1287/opre.47.2.183

Raghynathan, S. (2001). Information Sharing in A Supply Chain: A Note on its Value when Demand is No stationary. Management Science, 47(4), 605-610. http://dx.doi.org/10.1287/mnsc.47.4.605.9833

Tsay, A., \& Agrawal, N. (2004). Channel Conflict and Coordination in the E-commerce Age. Production and Operations Management, 13(1), 93-110. http://dx.doi.org/10.1111/j.1937-5956.2004.tb00147.x

Weng, Z. K. (1999). The power of coordinated decisions for short-life-cycle products in a manufacturing and distribution supply chain. IIE Transactions, 31, 1037-1049. http://dx.doi.org/10.1080/07408179908969905

Weng, Z. K., \& McClurg, T. (2003). Coordinated ordering decisions for short life cycle products with uncertainty in delivery time and demand. European Journal of Operational Research, 151, 12-24. http://dx.doi.org/10.1016/S0377-2217(02)00577-5

\section{Copyrights}

Copyright for this article is retained by the author(s), with first publication rights granted to the journal.

This is an open-access article distributed under the terms and conditions of the Creative Commons Attribution license (http://creativecommons.org/licenses/by/3.0/). 